\title{
Analisis Kesalahan Penggunaan Bahasa dalam Rencana AKhbar
}

\author{
Mohd Hazreen Shah Hassan \\ Universiti Putra Malaysia \\ mohdhazreenshahputra@gmail.com \\ Sharil Nizam Sha'ri \\ Universiti Putra Malaysia \\ sharil@upm.edu.my
}

\section{ABSTRACT \\ AN ANALYSIS ON LANGUAGE USAGE ERRORS IN NEWSPAPER FEATURE ARTICLES}

The medium that unites newspapers with its readers is correct language usage. Errors in language usage need to be minimized so that the message being conveyed is easily understood and accepted by the readers. This study was conducted to analyse the errors of language usage in newspaper feature articles, especially in terms of word choices and sentence formations by observing the criteria suggested by Waterhouse (1989). Using systematic sampling, a total of 20 newspaper feature articles in Berita Harian and Utusan Malaysia from 1 October to 30 November 2016 were studied. The results of the content analysis revealed that there were 128 errors related to the usage of language in the chosen newspaper feature articles. The errors related to sentence formation was the highest, with 60 errors, whereas the usage of synonym was the lowest, around three. Overall, the findings did not observe the criteria of an effective journalism writing, particularly in word choices and sentence formations, suggested by Waterhouse's (1989). Poor word choices might cause ambiguity and confusion among the readers while long-winded sentences and excessive explanations might cause the reader to lose focus thus failed to understand the content of the articles.

Keywords: newspaper, article writing, language, sentence formation, word choice

\section{PENGENALAN}

Rencana didefinisikan sebagai penulisan yang memprofilkan manusia sebagai berita, menerangkan kejadian yang menggerakkan berita, menganalisis apa-apa yang berlaku di dunia, negara dan masyarakat serta mengajar masyarakat berbuat sesuatu (Itule \& Anderson, 2007). Malah, penulisan rencana mencadangkan idea-idea yang lebih baik dalam dunia yang rumit, meneliti trend dalam masyarakat yang senantiasa berubah-ubah, membawa manusia ke 'alam' yang lain dan menghiburkan pembaca. Walaupun penulisan rencana dalam akhbar 
agak terbatas berbanding penulisan berita, penulisan rencana mempunyai fungsinya yang tersendiri untuk mempengaruhi minda pembaca.

Andi Baso (1994) menyatakan bahawa tujuan penulisan rencana adalah untuk memberitahu, menghibur, mendidik dan meyakinkan pembaca. Menurut Julia Wirza dan Kee (2013) pula, sifat penulisan kewartawanan itu sendiri sebagai penyebar maklumat secara tidak langsung akan membentuk pandangan dan pendapat umum tentang isu yang dibicarakan. Oleh hal yang demikian, bahasa memainkan peranan yang sangat penting dalam memastikan maklumat yang ingin disampaikan oleh penulis dapat difahami dan diterima oleh pembaca. Menurut Sharil Nizam (2010), penggunaan bahasa yang tepat, standard dan segar akan menghasilkan penulisan yang berpengaruh, diminati dan sukar dilupakan oleh pembaca. Oleh hal yang demikian, kesalahan penggunaan bahasa dalam penulisan rencana akan menjejaskan kelancaran penyampaian maklumat kepada pembaca.

Kesalahan bahasa dalam penulisan rencana lazimnya berlaku apabila penulis menggunakan kata umum, kata abstrak, kata tidak lazim, kata emotif dan dramatik, kata berangkai, kata sinonim, kata yang menunjukkan ketidakpastian, kata yang tidak jelas kuantitinya, disamping penggunaan jargon dan pembentukan ayat yang panjang. Ini menunjukkan bahawa seni berbahasa seseorang penulis rencana itu akan menentukan sejauh manakah penulisan rencana itu dapat menyampaikan maklumat dengan baik atau sebaliknya.

\section{PENYATAAN MASALAH}

Azean Idruwani dan Zaitul Azma Zainon (2011) menyatakan bahawa, bukan semua penulisan dalam akhbar menepati rumus tatabahasa Melayu, malah berlaku banyak kesalahan bahasa dalam penulisan kewartawanan yang dihasilkan. Kesalahan berbahasa yang berlaku mungkin disedari atau mungkin tidak disedari oleh penulis ataupun pembaca. Dapatan Li, Zhang dan Du (2014) mendapati bahawa penulis media kerap mencipta katakata baharu dalam penulisannya apabila tiada kata yang dapat menggambarkan idea yang ingin diketengahkan. Malah penggunaan perkataan yang tidak jelas (fuzzy words) juga tinggi sehingga menimbulkan kekeliruan dan kekaburan makna dalam kalangan pembaca. Agu (2015) menjelaskan bahawa sesetengah wartawan menggunakan perkataan yang klise dan jargon serta pembentukan ayat yang kompleks dalam penulisannya.

Sharil Nizam (2010) dan Hamidah (2012) pula menjelaskan bahawa kelewahan bahasa sering kali berlaku dalam penulisan kewartawanan sama ada pada penggunaan imbuhan, perkataan, frasa, ayat dan juga kelewahan dari segi pengulangan idea dalam penulisan. Hamidah (2012) turut menyatakan bahawa kelewahan akan mengganggu kepersisan ayat dan merencatkan pemahaman pembaca terhadap kandungan penulisan yang dihasilkan. Selain itu, Kartini dan Zulkifley (2015) mendapati bahawa faktor yang menghambat pemahaman dalam teks berita dalam kalangan pembaca berpunca daripada penggunaan perkataan tidak lazim, kelewahan imbuhan, penggunaan akronim yang tidak diketahui umum dan juga penggunaan kata pinjaman. Oleh itu, kajian ini menganalisis kesalahan penggunaan bahasa dalam rencana akhbar dari sudut pandangan Waterhouse (1989).

Kajian ini dijalankan bagi mencapai objektif berikut:

- Mengenal pasti kesalahan penggunaan kata dan pembentukan ayat dalam penulisan rencana akhbar. 
- Menganalisis jenis-jenis kesalahan dalam penulisan rencana akhbar berdasarkan perspektif Waterhouse (1989).

\section{SOROTAN KAJIAN}

Mohd Hazreen Shah, Sharil Nizam dan Nor Azuwan (2019) mendapati bahawa strategi yang berkesan dalam menghasilkan penulisan rencana kesihatan yang berpengaruh bergantung pada penggunaan kata yang tepat, mudah difahami dan diketahui umum, di samping pembentukan ayat yang jelas, padat, ringkas dan mengandungi penerangan yang sewajarnya. Penelitian menunjukkan bahawa lambakan jargon dalam penulisan rencana kesihatan menyukarkan pembaca untuk memahami kandungan rencana dengan berkesan. Oleh itu, mereka menyarankan penulis mengemukakan definisi yang sewajarnya apabila menggunakan istilah tersebut atau mencari padanan yang sesuai terhadap istilah perubatan dalam bahasa Melayu.

Di samping itu, Agu (2015) dalam kajiannya telah meneliti gaya pelaporan berita dalam akhbar dari sudut linguistik-stilistik. Hasil kajiannya mendapati bahawa gaya kepengarangan setiap penulis berita berkaitan undang-undang dan kehakiman adalah berbeza. Sesetengah penulis menulis dengan menggunakan pendekatan psikologi melalui pemilihan kata atau pembentukan ayat yang mewujudkan sentimen tertentu dan sesetengahnya pula menggunakan pendekatan yang berbentuk neutral atau objektif. Kajiannya juga mendapati bahawa terdapat penggunaan kata dan frasa berbunga-bunga (flowery words) dalam penulisan berita berkaitan undang-undang dan kehakiman. Baginya, penggunaan sesuatu istilah yang tidak biasa digunakan oleh pembaca akan menyebabkan mesej yang ingin disampaikan menjadi sia-sia.

Kajian oleh Li, Zhang dan Du (2014) telah mengenal pasti ciri-ciri leksikal dalam dua buah akhbar yang berlainan jenis, iaitu akhbar popular (popular newspapers) dan akhbar berkualiti (quality newspapers) dengan menggunakan pendekatan kontrastif. Hasil kajian mendapati bahawa terdapat pembentukan kata majmuk baharu yang dicipta oleh penulis sehingga menimbulkan kekaburan makna, malah penggunaan kata-kata yang tidak jelas pula memperlihatkan kekerapan yang tinggi bagi akhbar berkualiti berbandingan akhbar popular. Bagi mereka penggunaan sesuatu perkataan dalam penulisan kewartawanan mencerminkan perspektif dan pendirian seseorang penulis untuk menggilap perkembangan sesuatu bahasa, di samping membantu pembaca memahami kandungan dalam penulisan yang dihasilkan.

Menerusi kajian yang dijalankan oleh Ehineni (2014), aspek linguistik (leksikal dan struktur ayat) dalam akhbar perlu menitikberatkan aspek kesederhanaan dan kejelasan. Menurutnya lagi, pemilihan leksikal khususnya penggunaan singkatan dan akronim dalam penulisan kewartawanan perlu bersifat umum, malah penggunaan singkatan dan akronim yang tidak diketahui umum perlu dielakkan. Pembentukan ayat melalui proses pengguguran dan penggantian perlu tepat bagi mengelakkan berlakunya kekaburan makna terhadap mesej yang ingin disampaikan. Penelitian Bucaria (2004) pula mendapati bahawa kekaburan bahasa dalam aspek leksikal berpunca daripada penggunaan kata homonim, kata hubung, kata kerja dan kata nama yang mengandungi makna berganda (double meaning) dalam penulisan tajuk berita humor yang dihasilkan. Dalam aspek sintaksis pula, kekaburan bahasa berlaku apabila berlakunya perubahan penggolongan kata dalam pembentukan frasa tertentu pada kata-kata tertentu dan juga kesan elipsis dalam pembentukan ayat. 
Hamidah (2012) pula menyatakan bahawa, penggunaan bahasa yang jelas dan tepat amat penting bagi memastikan pembaca dapat memahami kandungan akhbar dengan baik. Menurutnya lagi, unsur kelewahan dalam penulisan kewartawanan perlu dielakkan bagi membentuk pemahaman yang menyeluruh terhadap kandungan akhbar. Kelewahan akan mengganggu kepersisan ayat dan turut merencatkan kefahaman pembaca terhadap kandungan akhbar itu sendiri. Walaupun penulis mempunyai kebebasan untuk melaporkan berita dengan menggunakan gaya bahasa dan kepengarangannya yang tersendiri, penekanan terhadap aspek bahasa juga perlu diberi perhatian yang sewajarnya, malah penggunaan kata yang membazir dalam pembentukan ayat perlu dielakkan bagi memastikan sesuatu penulisan itu padat dan ringkas serta mudah difahami oleh pembaca. Hal ini turut diakui oleh Sharil Nizam (2010) yang menyatakan bahawa dalam penulisan kewartawanan, berlakunya pembaziran bahasa, khususnya dalam aspek tatabahasa, leksikal dan ortografi. Jeniri (2005) menyatakan bahawa bahasa dalam akhbar adalah baku, iaitu tunduk kepada peraturan dan kaedah tertentu, bukannya berbentuk percakapan harian supaya lebih mudah untuk difahami oleh pembaca pembaca.

Secara keseluruhannya, kajian lepas berkaitan penulisan kewartawanan mendapati bahawa terdapay kesalahan dalam penggunaan bahasa sama ada dalam pemilihan kata dan juga pembentukan ayat. Kajian oleh Hamidah (2012) mendapati bahawa unsur kelewahan bahasa dalam akhbar masih tidak dapat dibendung. Dalam pada itu, masih berlakunya kesalahan berbahasa dalam akhbar sama ada dalam aspek penggunaan diksi, tatabahasa dan seumpamanya (Agu, 2015; Noordin, 2012; Eneng Khairunnisa, 2012; Azean Idruwani dan Zaitul Azma Zainon, 2011). Selain itu, Bucaria (2004) dalam kajiannya mendapati bahawa, wujudnya masalah kekaburan makna terhadap pembentukan ayat dalam penulisan kewartawanan. Hal ini menunjukkan bahawa kajian berkaitan kesalahan berbahasa dalam penulisan kewartawanan memerlukan kajian lanjutan agar kesalahan tersebut dapat dibendung daripada terus berlaku.

\section{METODOLOGI KAJIAN}

Kajian ini menggunakan kaedah analisis kandungan teks, kaedah pensampelan sistematik dan statistik mudah dalam menganalisis dan membincangkan data kajian. Dalam pada itu, alat kajian yang digunakan ialah dua buah akhbar berbahasa Melayu, iaitu Berita Harian (BH) dan Utusan Malaysia (UM) yang diterbitkan sepanjang 1 Oktober 2016 sehingga 30 November 2016. Walau bagaimanapun, kajian ini berfokus pada rencana sahaja sebagai data kajian. Bagi akhbar $B H$, segmen rencana dalam akhbar tersebut dikenali dengan segmen "Dari Kaca Mata", manakala akhbar UM memperkenalkan segmen khas "Rencana". Kedua-dua segmen ini akan dijadikan sebagai sampel dalam kajian ini. Secara keseluruhannya, jumlah rencana yang terdapat dalam kedua-dua akhbar ini sepanjang Oktober dan Novermber 2016 adalah sebanyak 242 buah (51 BH : 191 UM). Daripada jumlah tersebut, sebanyak 20 buah rencana sahaja dikaji sebagai sampel kajian. Bagi mengimbangi sampel kajian, pengkaji telah membahagikan nisbah sampel kajian kepada 1:1, iaitu sepuluh (10) daripada akhbar BH dan sepuluh (10) lagi daripada akhbar UM. Pensampelan sistematik digunakan dengan menggunakan formula saiz selang sampel (sampling interval) seperti berikut: 


$$
\begin{aligned}
\text { Saiz Selang Sampel } & =\mathrm{K} \\
\mathrm{k} & =\mathrm{N} / \mathrm{n}
\end{aligned}
$$

(Sumber: Noor Aina Dani, 2008)

\begin{aligned} & Akhbar $B H \\ & \mathrm{k}= 51 / 10 \\ &= 5.1 \\ &= 5$ buah rencana \\ & \hline\end{aligned}

\begin{aligned} & Akhbar UM \\ & $\mathrm{k}= 191 / 10 \\ &= 19.1 \\ &= 19$ buah rencana \\ & \hline\end{aligned}

Rencana untuk kajian ini dipilih berdasarkan saiz selang sampel tersebut. Jadual 1 dan 2 menunjukkan rangka pemilihan rencana bagi akhbar $B H$ dan akhbar UM.

Jadual 1: Rangka Pemilihan Sampel bagi Akhbar $B H$

$\begin{array}{ccccc}\text { Sampel Dipilih } & \rightarrow & \text { Selang Sampel } & = & \text { Sampel Kajian bagi } \boldsymbol{B} \boldsymbol{H} \\ \text { Sampel 1 } & \rightarrow & 1 & = & \text { Rencana 1 } \\ \text { Sampel 2 } & \rightarrow & 1+5 & = & \text { Rencana 6 } \\ \text { Sampel 3 } & \rightarrow & 6+5 & = & \text { Rencana 11 } \\ \text { Sampel 4 } & \rightarrow & 11+5 & = & \text { Rencana 16 } \\ \text { Sampel 5 } & \rightarrow & 16+5 & = & \text { Rencana 21 } \\ \ldots & \rightarrow & \ldots & = & \ldots \\ \text { Sampel 10 } & \rightarrow & 41+5 & = & \text { Rencana 46 }\end{array}$

Jadual 2: Rangka Pemilihan Sampel bagi Akhbar UM

\begin{tabular}{ccccc} 
Sampel Dipilih & $\rightarrow$ & Selang Sampel & $=$ & Sampel Kajian bagi $\boldsymbol{U M}$ \\
Sampel 1 & $\rightarrow$ & 1 & $=$ & Rencana 1 \\
Sampel 2 & $\rightarrow$ & $1+19$ & $=$ & Rencana 20 \\
Sampel 3 & $\rightarrow$ & $20+19$ & $=$ & Rencana 39 \\
Sampel 4 & $\rightarrow$ & $39+19$ & $=$ & Rencana 58 \\
Sampel 5 & $\rightarrow$ & $58+19$ & $=$ & Rencana 77 \\
$\ldots$ & $\rightarrow$ & $\ldots$ & $=$ & $\ldots$ \\
Sampel 10 & $\rightarrow$ & $153+19$ & $=$ & Rencana 172 \\
\hline
\end{tabular}

Setelah membuat pemilihan sampel, analisis kandungan teks dilakukan. Kajian ini menggunakan pendekatan yang dikemukakan oleh Waterhouse (1989), iaitu Ciri-ciri Bahasa Penulisan Kewartawanan dalam menganalisis rencana yang dipilih. Ciri-ciri tersebut ialah menggunakan kata khusus, bukan umum; menggunakan kata konkrit, bukan abstrak; 
menggunakan kata biasa, bukan kata tidak lazim; dan menggunakan pernyataan secara positif, bukan secara negatif. Selain itu, penulisan kewartawananp perlu menggelakkan penggunaan kata emotif dan dramatik; penggunaan perkataan yang berangkaian untuk menyatakan sesuatu maksud yang mudah; penggunaan perkataan yang membawa makna yang sama; penggunaan perkataan yang menunjukkan ketidakpastian; dan penggunaan perkataan yang tidak jelas kuantitinya. Perkataan yang betul ejaannya dan maknanya perlu digunakan di samping mengelakkan penggunaan jargon dan perkataan yang klise.

Walau bagaimanapun, dalam kajian ini, pendekatan ini diubah suai supaya bertepatan dengan data kajian yang diperoleh. Nor Azuwan (2008) menjelaskan bahawa pengubahsuaian terhadap sesuatu kerangka kajian dilakukan supaya kajian yang dijalankan tidak bersifat memaksa data untuk menurut kerangka yang dikemukakan, sebaliknya pendekatan yang digunakan selari dengan korpus data kajian. Oleh itu, aspek-aspek bahasa yang dilihat dalam kajian ini terbahagi kepada tujuh (7) aspek, iaitu penggunaan kata umum atau abstrak; penggunaan kata tidak lazim; penggunaan kata sinonim; penggunaan kata yang menunjukkan ketidakpastian; penggunaan istilah jargon; penerangan ayat yang berlebihlebihan; dan kesalahan ejaan. Kesalahan tatabahasa tidak akan dianalisis dan diperbetul memandangkan kajian ini hanya memfokuskan kesalahan penggunaan bahasaa.

\section{DAPATAN KAJIAN}

Berdasarkan analisis yang dilakukan, sebanyak 128 penggunaan kata atau ayat didapati tidak menepati saranan Waterhouse (1989). Daripada jumlah tersebut, akhbar UM mencatatkan jumlah tertinggi, iaitu sebanyak 75 penggunaan kata atau ayat bersamaan dengan 59\% berbanding akhbar $\mathrm{BH}$, sebanyak 53 penggunaan kata atau ayat, iaitu 41\% (lihat Rajah 1).

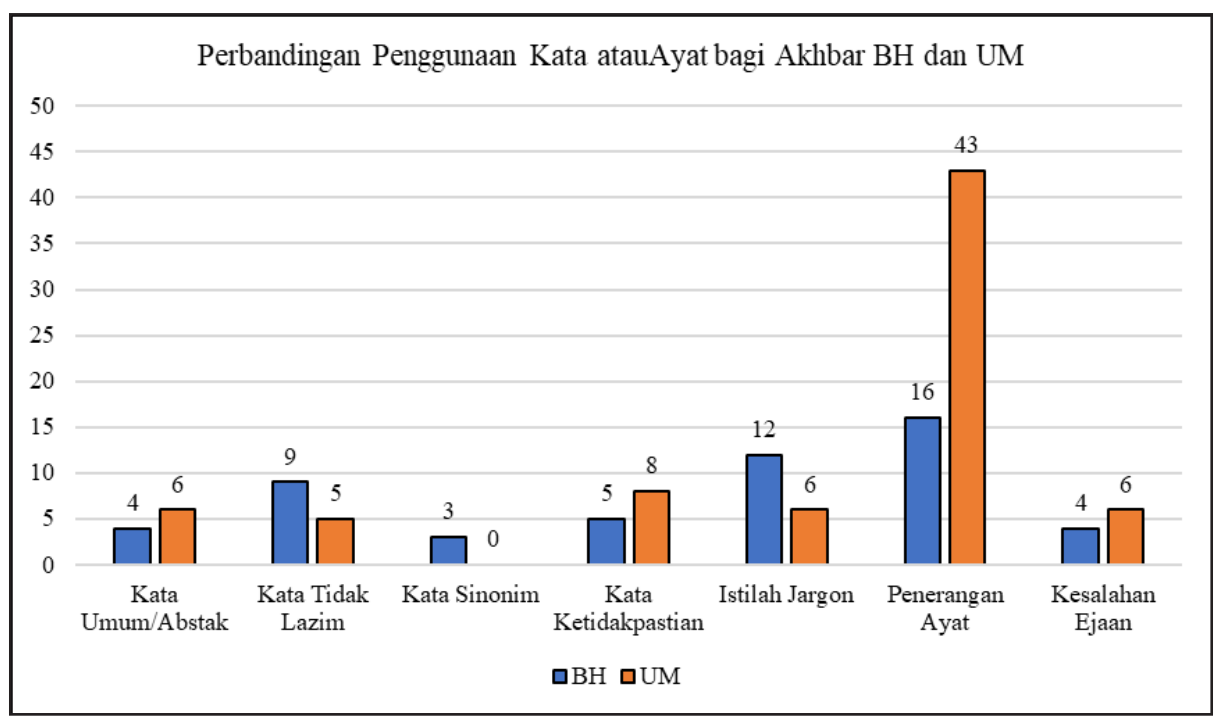

\section{Rajah 1: Perbandingan Penggunaan Kata atau ayat bagi Akhbar $B H$ dan $U M$}

Bagi akhbar UM, kesalahan yang paling banyak melibatkan penerangan ayat, iaitu sebanyak 44 penggunaan (59\%), diikuti dengan penggunaan kata yang menunjukkan ketidakpastian sebanyak lapan penggunaan (11\%). Kesalahan dari aspek penggunaan kata umum atau 
abstrak, jargon dan kesalahan ejaan pula masing-masing adalah sebanyak enam penggunaan, atau lapan peratus (8\%) manakala penggunaan kata tidak lazim adalah sebanyak lima penggunaan, iaitu tujuh peratus (7\%). Penggunaan kata sinonim tidak ditemui dalam akhbar UM.

Bagi akhbar $B H$ pula, jumlah tertinggi bagi penggunaan kata atau ayat yang tidak menepati saranan Waterhouse (1989) membabitkan penerangan ayat, iaitu sebanyak 16 penggunaan (30\%), penggunaan kata tidak lazim sebanyak 12 penggunaan (23\%). Penggunaan istilah jargon pula adalah sebanyak $23 \%$ daripada jumlah keseluruhan data bagi akhbar $B H$. Selain itu, penggunaan kata umum atau abstrak dan kesalahan ejaan masingmasing mencatatkan empat penggunaan. Bagi kata yang menunjukkan ketidakpastian pula, sebanyak lima penggunaan bersamaan dengan sembilan peratus $(9 \%)$ ditemui. Yang terendah, ialah penggunaan kata sinonim, iaitu sebanyak tiga penggunaan $(6 \%)$.

\title{
Penggunaan Kata Umum atau Abstrak (KUA)
}

Waterhouse (1989) menyarankan penulis untuk menggunakan kata khusus dan konkrit serta mengelakkan penggunaan kata umum dan abstrak dalam penulisan kewartawanan. Berikut merupakan dua contoh petikan yang menunjukkan penggunaan kata umum atau abstrak:

\begin{abstract}
Data 1 KUA:
“...Persoalan yang begitu kompleks dihadapi dunia pada abad ke-21 ini, menuntut kepada suatu bentuk pemikiran baharu yang luhur dan benar-benar tuntas untuk mencari penyelesaian terbaik terhadap isu yang melanda..." (BH, 27 Oktober 2016).
\end{abstract}

Data 2 KUA:

“...Lantas, dalam menyentuh isu berkait dengan pelajar di universiti awam (UA) pada masa kini yang dilihat terlalu 'dimanjakan', kegagalan pensyarah dan pembimbing dalam menyediakan ilmu yang benar-benar bermanfaat...” (BH , 27 Oktober 2016).

Perkataan luhur dalam petikan rencana Data 1 KUA merupakan contoh penggunaan kata umum atau abstrak. Perkataan luhur dikategorikan sebagai kata adjektif sifatan yang menunjukkan suatu perihal yang mulia, tinggi dan agung (Kamus Dewan Edisi Keempat, 2015). Penggunaan kata adjektif tersebut tidak membawa makna yang khusus terhadap maksud keseluruhan ayat. Ayat tersebut menjelaskan sesuatu perkara berkaitan dengan 'bentuk pemikiran'. Roslan dan Siti Khariah (2007) menjelaskan bahawa pemikiran yang luhur merujuk kepada suatu konsep berkaitan ketuhanan, keimanan, keagamaan, ketauhidan dan keesaan Tuhan sedangkan keseluruhan ayat tidak membincangkan perihal tersebut. Ayat tersebut membincangkan suatu perkara berkaitan bentuk pemikiran yang baru. Oleh hal yang demikian, penggunaan luhur dalam ayat tersebut didapati tidak sesuai untuk menggambarkan maksud keseluruhan ayat. Penggunaan kata yang khusus sifatnya seperti kata bernas, tepat dan baik adalah antara contoh pilihan kata yang wajar digunakan bagi menggambarkan maksud keseluruhan ayat dengan lebih tepat.

Bagi Data 2 KUA, kata umum atau abstrak dalam ayat tersebut ialah kata pelajar. Menurut Kamus Dewan Edisi Keempat (2015), pelajar merupakan orang yang belajar seperti murid sekolah, penuntut di maktab dan sebagainya. Oleh itu, bagi memperlihatkan fokus subjek dalam ayat ini yang membicarakan 'pelajar di universiti awam (UA)', justeru, 
penggunaan kata mahasiswa dilihat lebih sesuai sebagai subjek dalam ayat dan membawa maksud yang lebih khusus berbanding penggunaan kata pelajar. Menurut Kamus Dewan Edisi Keempat (2015), mahasiswa merujuk kepada pelajar atau penuntut di universiti.

\title{
Penggunaan Kata Tidak Lazim (KTL)
}

Menurut Nurhidayah (2006), kata lazim merupakan kata yang sudah dikenali dan digunakan oleh seluruh masyarakat secara meluas, manakala kata tidak lazim pula merupakan kata yang kurang digunakan oleh masyarakat secara meluas dan hanya digunakan oleh golongan tertentu sahaja. Dalam analisis ini, sebanyak 14 penggunaan kata tidak lazim dikenal pasti dalam penulisan rencana yang dikaji. Daripada jumlah tersebut, akhbar $\mathrm{BH}$ mencatatkan jumlah tertinggi dengan sembilan penggunaan berbanding akhbar UM yang mencatatkan sebanyak lima penggunaan sahaja. Berikut merupakan contoh beberapa petikan yang menunjukkan penggunaan kata tidak lazim dalam rencana yang dianalisis.

\begin{abstract}
Data 1 KTL:
"Endowmen sejak sekian lama adalah dana kewangan dan rizab aset yang diagregasikan sesebuah universiti khususnya universiti ternama seperti Harvard, Oxford dan Yale untuk menyokong dan membiayai misi pendidikannya secara konsisten daripada penyumbang individu dan korporat..." (BH, 01 Oktober 2016).
\end{abstract}

\section{Data 2 KTL:}

Selain membincang dan menilai tahap apresiasi rakyat Kelantan terhadap projekprojek pembangunan yang dilaksanakan oleh Kerajaan Persekutuan, Konvensyen UMNO Kelantan yang bakal dilangsungkan sehari suntuk itu juga wajar memberi lebih banyak ruang untuk ahli parti 'bermuhasabah diri' demi kebaikan bersama (UM, 12 Oktober 2016).

Bagi Data $1 \mathrm{KTL}$, kata tidak lazim dalam petikan di atas ialah diagregasikan. Kata diagregasikan merupakan kata terbitan daripada kata dasar agregasi yang telah menerima imbuhan apitan di-...-kan yang diklasifikasikan sebagai kata kerja. Kata agregasi merujuk pada pengumpulan sejumlah benda yang terpisah-pisah menjadi satu; sejumlah tumbuhan atau binatang yang merupakan suatu kesatuan dalam kelompok yang lebih besar (Kamus Besar Bahasa Indonesia Edisi Keempat, 2008). Berdasarkan definisi tersebut, jelas bahawa diagrerasikan merupakan satu perihal yang menunjukkan perbuatan mengumpul atau menghimpunkan sesuatu. Kata tersebut merupakan kata tidak lazim kerana tidak digunakan secara meluas dalam kalangan masyarakat sekali gus mungkin menyukarkan pembaca untuk memahami kandungan rencana itu dengan baik. Oleh hal yang demikian, kata diagregasikan mungkin boleh digantikan dengan kata yang lazim digunakan dan diketahui oleh masyarakat seperti kata dikumpulkan atau dihimpunkan bagi memudahkan pembaca memahami kandungan rencana dengan lebih baik.

Bagi Data $2 \mathrm{KTL}$, contoh kata tidak lazim yang digunakan dalam petikan tersebut ialah apresiasi. Apresiasi merujuk pada suatu penghargaan terhadap sumbangan atau jasa seseorang atau sesuatu pihak; pengiktirafan serta penghayatan nilai sesuatu karya sastera atau seni (Kamus Dewan Edisi Keempat, 2015). Perkataan apresiasi tidak digunakan oleh masyarakat secara meluas, khususnya ketika berkomunikasi. Pembaca mungkin lebih mudah untuk memahami kandungan rencana jika penulis menggunakan perkataan lazim seperti 
penerimaan atau kepuasan dalam pembentukan ayat tersebut.

Secara keseluruhannya, penggunaan kata tidak lazim dalam penulisan rencana akan menyukarkan pembaca untuk memahami kandungan rencana dengan lebih jelas dan tepat. Menurut Mohd Rajib dan Faridah (1987), bagi mengelakkan berlakunya kekeliruan dan kemungkinan salah bahasa dalam penulisan kewartawanan, penulis tidak boleh menggunakan ungkapan atau kata-kata yang tidak difahami oleh pembaca. Oleh hal yang demikian, perkataan yang biasa atau lazim digunakan oleh orang ramai perlu digunakan agar kandungan rencana lebih mudah untuk difahami.

\section{Penggunaan Kata Sinonim (KS)}

Kata sinonim merupakan 'ungkapan atau kata-kata yang maknanya hampir sama dengan ungkapan atau kata-kata yang lain', malah penggunaannya ditentukan mengikut konteks dan situasi (Goay, Lee \& Zainuddin, 2006). Hasil analisis mendapati bahawa hanya akhbar BH sahaja yang ada menggunakan kata sinonim dalam rencana yang dikaji. Petikan di bawah merupakan contoh penggunaan kata sinonim yang terdapat dalam rencana akhbar $\mathrm{BH}$ :

\section{Data $1 \mathrm{KS}$ :}

“Peningkatan kos pendidikan dan biasiswa yang terhad tidak boleh dijadikan alasan untuk berhutang sekiranya kita mempunyai pilihan untuk menyimpan wang atau menabung sejak dari awal..." (BH, 13 Oktober 2016).

\section{Data 2 KS: \\ “...Lantas, dalam menyentuh isu berkait dengan pelajar di universiti awam (UA) pada masa kini yang dilihat terlalu 'dimanjakan', kegagalan pensyarah dan pembimbing dalam menyediakan ilmu yang benar-benar bermanfaat dan dapat dimanfaatkan oleh pelajar kelak akan menimbulkan keruntuhan ketamadunan yang lebih parah untuk masa depan negara kita ini kerana mereka yang akan menjadi penyambung dan wadah keintelektualan untuk generasi seterusnya" (BH, 27 Oktober 2016).}

Bagi Data $1 \mathrm{KS}$, kata sinonim yang dikenal pasti ialah menyimpan dan menabung. Kamus Dewan Edisi Keempat (2015) mendefinisikan menyimpan kepada dua, iaitu menaruh di tempat yang selamat; dan menghimpun wang atau menabung. Kata menabung pula merujuk kepada suatu perihal menyimpan wang di dalam bank, tabung dan lain-lain (Kamus Dewan Edisi Keempat, 2015). Berdasarkan definisi tersebut, jelas bahawa kedua-dua perkataan tersebut merujuk pada satu perbuatan yang sama, iaitu suatu perihal mengumpulkan atau menyisihkan sejumlah wang untuk disimpan di tempat yang selamat.

Penggunaan perkataan pensyarah dan pembimbing dalam Data 2 KS merupakan contoh lain kata sinonim dalam penulisan rencana. Menurut Kamus Dewan Edisi Keempat (2015), kata pensyarah merujuk kepada guru di universiti dan kata pembimbing pula merujuk kepada orang yang membimbing. Jika dilihat pada petikan di atas, kedua-dua kata ini merujuk kepada individu yang sama, iaitu tenaga pengajar di universiti. Oleh hal yang demikian, bagi memudahkan proses pemahaman dalam kalangan pembaca, penggunaan kata tenaga pengajar dilihat lebih tepat untuk menjelaskan kandungan rencana. Kamus Dewan Edisi Keempat (2015) mendefinisikan kata tenaga pengajar sebagai orang yang ahli atau berkelayakan untuk mengajarkan sesuatu mata pelajaran, bidang ilmu, kemahiran dan sebagainya. Oleh 
itu, penggunaan kata tenaga pengajar lebih khusus sifatnya kerana perkataan itu mendukung makna bagi kedua-dua kata tersebut.

Penggunaan kata sinonim dalam penulisan rencana akan menyebabkan struktur ayat menjadi lewah dan tidak gramatis. Hal ini diperkatakan oleh Zaharani (2002), iaitu kelewahan akan mengganggu kegramatisan ayat dan hal ini menyalahi rumus tatabahasa Melayu. Hamidah (2012) menjelaskan bahawa kelewahan bahasa dalam penulisan kewartawanan perlu dielakkan bagi membentuk pemahaman yang lebih baik kepada pembaca, bukan sahaja dari segi kandungannya, malah dalam konteks penggunaan bahasanya.

\section{Penggunaan Kata yang Menunjukkan Ketidakpastian (KK)}

Menurut Hasna (2013), penggunaan kata yang menunjukkan ketidakpastian merupakan kata yang menghubungkan bahagian dalam sesebuah wacana yang menunjukkan satu hal yang tidak pasti atau menggambarkan keraguan seperti mungkin dan barangkali. Oleh hal yang demikian, bagi membentuk suatu ayat yang menunjukkan kepastian, kata mungkin dan barangkali wajar digugurkan dan digantikan dengan kata lain yang berupaya menjelaskan kepersisan kandungan ayat. Berikut merupakan contoh petikan yang mengandungi kata yang menunjukkan ketidakpastian:

\section{Data $1 \mathrm{KK}$ :}

"Berhutang mungkin boleh menjadi pilihan akhir jika tabungan tidak mencukupi tetapi ia bukanlah menjadi pilihan utama atau satu-satunya pilihan untuk kita..." (BH, 13 Oktober 2016).

\section{Data 2 KK:}

“...di negara kita sudah bina hampir 4.5 juta rumah dalam tempoh 38 tahun. Barangkali senario di luar negara berlainan dengan suasana di negara kita..." (BH, 7 November 2016).

\section{Data 3 KK:}

"Mungkin banyak lagi 'produk' yang boleh difikir untuk masa depan rakyat Kelantan jika BN berjaya kembali menerajui Kelantan..." (UM, 12 Oktober 2016).

\section{Data 4 KK:}

"Ini barangkali akan membantu menjawab persoalan 'mengapakah JKNMPP ini menetapkan RM3,000 sebagai angka imbuhan penanda aras untuk dilapor..." (UM, 18 Oktober 2016).

Bagi Data 1 KK, Data 2 KK dan Data 4 KK, kata mungkin dan barangkali dalam ayat tersebut wajar digugurkan bagi membentuk satu ayat yang tidak menimbulkan keraguan atau ketidakpastian. Namun begitu, bagi Data 3 KK pula, mungkin boleh digantikan dengan hakikatnya kerana perkataan tersebut berlawanan dengan mungkin yang merujuk kepada sesuatu yang sudah nyata, kebenaran atau kenyataan (Kamus Dewa Edisi Keempat, 2015). Oleh itu, ayat-ayat di atas boleh ditulis seperti berikut bagi membentuk ayat yang tidak menunjukkan keraguan atau ketidakpastian: 
- "Berhutang boleh menjadi pilihan akhir jika tabungan tidak mencukupi tetapi ia bukanlah menjadi pilihan utama atau satu-satunya pilihan untuk kita..."

- "...di negara kita sudah bina hampir 4.5 juta rumah dalam tempoh 38 tahun. Senario di luar negara berlainan dengan suasana di negara kita..."

- "Hakikatnya, banyak lagi 'produk' yang boleh difikir untuk masa depan rakyat Kelantan jika BN berjaya kembali menerajui Kelantan..."

- "Ini akan membantu menjawab persoalan 'mengapakah JKNMPP ini menetapkan RM3,000 sebagai angka imbuhan penanda aras untuk dilapor..."

Penggunaan kata yang menunjukkan ketidakpastian dalam penulisan kewartawanan menyebabkan pembaca menjadi was-was dan ragu-ragu terhadap kandungan penulisan rencana. Oleh itu, penulis perlu mengelakkan penggunaan kata yang menunjukkan ketidakpastian supaya pembaca tidak berasa was-was atau ragu-ragu apabila membaca penulisan yang dihasilkan.

\section{Penggunaan Perkataan Jargon (PJ)}

Jargon merujuk pada penggunaan istilah khusus dan teknikal dalam bidang tertentu, tetapi tidak digunakan dan difahami secara meluas oleh kebanyakan masyarakat (Roosfa, 2011). Hasil analisis menunjukkan bahawa penggunaan jargon dalam akhbar BH lebih tinggi (12 penggunaan) berbanding akhbar UM (enam sahaja). Berikut merupakan contoh petikan yang mengandugi jargon dalam rencana yang dianalisis:

\section{Data 1 IJ:}

“Teras kritikal dalam senarai itu ialah perangkaan statut baharu yang akan dinamakan Akta Sumbangan dan Perbelanjaan Politik (PDEA)..." (BH , 19 Oktober 2016).

\section{Data 2 IJ:}

“Bab enam pula menerangkan prinsip yang menjadi panduan kepada regulasi pembiayaan politik...." ( UM, 18 Oktober 2016).

Berdasarkan Data $1 \mathrm{KJ}$, perkataan jargon ialah statut. Perkataan statut merupakan istilah teknikal dalam bidang perundangan. Kamus Dewan Edisi Keempat (2015) mendefinisikan statut sebagai undang-undang bertulis yang diluluskan oleh Parlimen atau badan lain yang berkuasa membuat undang-undang. Jargon dalam Data 2 IJ pula ialah regulasi. Berdasarkan konteks ayat, istilah regulasi merujuk pada suatu peraturan yang dicipta untuk kelangsungan hidup masyarakat (Kamus Besar Bahasa Indonesia Edisi Keempat, 2008). Oleh itu, berikut merupakan cadangan bagi menggantikan penggunaan jargon:

\section{Data 1 IJ:}

- “Teras kritikal dalam senarai itu ialah perangkaan statut (perundangan) baharu yang akan dinamakan Akta Sumbangan dan Perbelanjaan Politik (PDEA)...", atau

- "Teras kritikal dalam senarai itu ialah perangkaan perundangan baharu yang akan dinamakan Akta Sumbangan dan Perbelanjaan Politik (PDEA)..." 
Data 2 IJ:

- “Bab enam pula menerangkan prinsip yang menjadi panduan kepada regulasi (peraturan) pembiayaan politik...."; atau

- "Bab enam pula menerangkan prinsip yang menjadi panduan kepada peraturan pembiayaan politik...."

Bagi memudahkan pembaca memahami kandungan rencana dengan lebih baik, penggunaan istilah jargon seharusnya disertakan dengan maknanya. Selain itu, penulis boleh menggunakan kata atau istilah lain yang diketahui umum.

\section{Kesalahan Ejaan (KE)}

Nor Azuwan (2008) menjelaskan bahawa aspek ejaan dalam penulisan kewartawanan perlulah berasaskan sistem yang telah dikodifikasikan serta digunakan dalam pelbagai bidang. Kesalahan ejaan dalam sesuatu bentuk penulisan akan mengganggu kelancaran pembaca untuk memahami fakta-fakta dengan baik (Paimah, 2004). Berikut merupakan contoh petikan yang mengandungi kesalahan ejaan dalam rencana yang dikaji:

\section{Data $1 \mathrm{KE}$ :}

Ini bermakna corak pemikiran dan pandang dunia atau welstanchuung perlu berubah mengikut keadaan dan tuntutan dunia semasa berteraskan perspektif transdisiplin dan tidak lagi terikat serta terkongkong dengan pemikiran sektoral (BH , 27 Oktober 2016).

\section{Data 2 KE:}

Dunia berada di ambang ketidakpastian dan ramai masih mentelaah dan mencongak apa yang akan berlaku di Amerika Syarikat (AS) khususnya dan dunia amnya berikutan kemenangan mengejut dicapai Donald Trump dalam Pilihan Raya Presiden AS Ke-45 baru-baru ini, mengalahkan calon popular Hillary Clinton $(B H$, 24 November 2016).

Bagi Data $1 \mathrm{KE}$, kesalahan ejaan terdapat pada perkataan welstanchuung. Ejaan sebenar bagi perkataan tersebut ialah weltanschauung. Perkataaan weltanschauung merupakan kata pinjaman daripada bahasa Jerman yang merujuk pada pandangan menyeluruh, terutama bagi seseorang individu terhadap kehidupan manusia dan alam sejagat (Kamus Dewan Edisi Keempat, 2015).

Seterusnya, kesalahan ejaan bagi Data 2 KE ialah mentelaah. Perkataan mentelaah merupakan kata terbitan daripada kata dasar telaah yang menerima imbuhan awalan meNyang diklasifikasikan sebagai kata kerja. Menurut Nik Safiah Karim et al. (2011), imbuhan awalan meN- akan menjadi me- apabila bergabung dengan kata dasar yang dimulai dengan huruf $t$. Dalam pada itu, huruf pertama pada kata dasar tersebut digugurkan dan digantikan dengan bentuk sengau yang sama daerah artikulasinya dengan huruf pertama kata dasar tersebut; misalnya, huruf $t$ digantikan dengan huruf $n$ (Nik Safiah Karim et al., 2011). Berikut merupakan rumus ejaan kata terbitan yang menerima imbuhan awalan meN-:

$$
\text { meN- (menjadi me-) }+ \text { telaah }(t \text { digantikan dengan huruf } n) \rightarrow \text { menelaah }
$$


Oleh itu, ejaan yang betul bagi kata dasar telaah yang menerima imbuhan awalan meN- ialah menelaah, bukannya mentelaah.

\section{Penerangan Ayat yang Berlebih-Lebihan (PA)}

Kepanjangan dan struktur ayat dalam penulisan kewartawanan hendaklah ringkas dan kebiasaannya bersifat singkat. Yang ditekankan dalam penulisan kewartawanan ialah kejelasan maklumat yang ingin disampaikan kepada pembaca (Nor Azuwan, 2008). Oleh hal yang demikian, jumlah maksimum perkataan bagi sesebuah ayat dalam penulisan kewartawanan ialah 30 patah perkataan dan ayat yang melebihi jumlah tersebut telah membentuk ayat kompleks dan kabur maknanya (Baker-Woods et al., 1977). Analisis kajian mendapati bahawa kesalahan ini merupakan kesalahan paling dominan dalam kedua-dua akhbar. Akhbar BH mencatatkan sebanyak 16 kesalahan penerangan ayat yang berlebihlebihan, manakala akhbar UM pula merekodkan sebanyak 44 kesalahan. Berikut merupakan contoh petikan yang mengandungi penerangan ayat yang berlebih-lebihan dalam rencana yang dianalisis:

\section{Data 1 PA}

“Dunia berada di ambang ketidakpastian dan ramai masih mentelaah dan mencongak apa yang akan berlaku di Amerika Syarikat (AS) khususnya dan dunia amnya berikutan kemenangan mengejut dicapai Donald Trump dalam Pilihan Raya Presiden AS Ke-45 baru-baru ini, mengalahkan calon popular Hillary Clinton" (BH, 24 November 2016).

Data 1 PA di atas mengandungi 34 patah perkataan. Dari segi pembentukan ayat, penulis menggunakan ayat majmuk campuran yang ditandai dengan kata hubung 'dan' yang menyebabkan ayat tersebut mengandungi penerangan yang berlebih-lebihan. Oleh itu, bagi memudahkan pembaca untuk memahami kandungan rencana dengan baik, maka, petikan tersebut perlu diringkaskan seperti petikan di bawah:

“Dunia berada di ambang ketidakpastian (5 patah perkataan). Ramai masih menelaah dan mencongak perkara yang akan berlaku di Amerika Syarikat (AS) dan dunia kesan kemenangan mengejut Donald Trump dalam Pilihan Raya Presiden AS Ke-45 baru-baru ini setelah mengalahkan calon popular, Hillary Clinton (27 patah perkataan)."

Berdasarkan pembetulan bagi Data 1 PA, ayat yang pada awalnya mengandungi sebanyak 34 patah perkataan telah dipecahkan kepada dua ayat agar kandungan rencana tersebut lebih mudah difahami: ayat pertama mengandungi lima patah perkataan manakala ayat kedua pula mengandungi 27 patah perkataan.

\section{Data 2 PA:}

"Sehubungan itu, sekiranya berlaku sebarang masalah pada mana-mana kapal termasuklah jika membabitkan insiden rompakan atau penculikan, kapal yang dilengkapi dengan AIS dan alat komunikasi boleh segera menghubungi pihak berkuasa bagi meminta bantuan manakala pasukan yang dihantar akan lebih mudah 
bertindak kerana telah mempunyai maklumat lengkap mengenai kapal berkenaan" (UM, 2 Oktober 2016).

Bagi Data 2 PA, jumlah perkataan bagi petikan tersebut adalah sebanyak 48 patah perkataan. Selain penerangan yang berlebih-lebihan, terdapat juga beberapa kesalahan lain seperti penggunaan kata sinonim yang menyebabkan struktur ayat tersebut menjadi lewah. Oleh itu, bagi memudahkan pembaca untuk memahami kandungan rencana dengan baik, maka, petikan tersebut boleh diringkaskan seperti petikan di bawah:

"Sekiranya berlaku sebarang masalah pada kapal, termasuklah insiden rompakan atau penculikan, kapal yang dilengkapi dengan AIS dan alat komunikasi boleh segera menghubungi pihak berkuasa bagi meminta bantuan (27 patah perkataan). Selain itu, pasukan penyelamat akan lebih mudah bertindak kerana mereka mempunyai maklumat lengkap mengenai kapal berkenaan (16 patah perkataan)."

Berdasarkan pembetulan pembentukan ayat bagi Data 2 PA, ayat yang pada awalnya mengandungi sebanyak 48 patah perkataan telah dikurangkan kepada 43 patah perkataan dan pengkaji membahagikan ayat tersebut kepada dua bentuk ayat agar kandungan rencana lebih mudah untuk difahami dengan masing-masing 27 patah perkataan dan 16 patah perkataan.

Secara keseluruhannya, kebolehan untuk menghasilkan ayat yang sempurna dalam sesuatu penulisan amat penting. Paimah (2004) menyatakan bahawa, pembaca akan gagal menghayati sesuatu ayat jika ayat itu mengandungi deretan fakta, malah pembaca juga akan mengalami kesukaran untuk memahami ayat tersebut jika ayat tersebut tidak mantap dan tergantung. Oleh hal yang demikian, penulis perlu mengelakkan penerangan ayat yang berlebih-lebihan dan menitikberatkan penggunaan ayat yang singkat dalam pembentukan sesuatu ayat seperti yang disarankan oleh Waterhouse (1989).

\section{KESIMPULAN}

Secara keseluruhannya, kesalahan penggunaan bahasa dalam penulisan rencana masih berlaku. Berdasarkan analisis penggunaan bahasa daripada perspektif Waterhouse (1989), kesalahan dalam pemilihan kata menyebabkan pembaca mengalami kekaburan dan kekeliruan makna terhadap kata yang digunakan. Penggunaan kata-kata bersifat umum atau abstrak, jargon dan tidak lazim perlu diberikan penjelasan atau definisi yang sewajarnya bagi memudahkan pembaca memahami kandungan rencana. Di samping itu, pembentukan ayat yang panjang dan mengandungi penerangan yang berlebih-lebihan pula menyebabkan pembaca hilang tumpuan untuk memahami kandungan rencana dengan baik. Oleh hal yang demikian, penulis disarankan untuk membentuk ayat yang ringkas dan mengelakkan daripada mengemukakan beberapa gagasan idea dalam satu ayat. Ciri-ciri bahasa penulisan kewartawanan yang dikemukakan oleh Waterhouse (1989) merupakan satu garis panduan yang boleh dijadikan pegangan dalam kalangan penulis untuk menghasilkan penulisan kewartawanan yang berkesan, khususnya dari aspek pemilihan kata dan pembentukan ayat. Hakikatnya, penggunaan kata yang tepat dan pembentukan ayat yang jelas berupaya menjelaskan kandungan rencana dengan efektif. Pemilihan kata yang kurang sesuai 
dan digunakan bukan pada tempatnya akan menjejaskan kualiti penulisan, manakala pembentukan ayat yang panjang akan mengganggu pemahaman pembaca.

\section{RUJUKAN}

Agu, I. E. (2015). A linguistic-stylistic analysis of newspaper reportage. International Journal of Research in Humanities and Social Studies, 2(8), 20-27.

Andi Baso Mappatoto. (1994). Teknik penulisan feature (karangan khas). Jakarta: Gramedia Pustaka Utama.

Arba'ie Sujud. (2010). Perpaduan masyarakat dalam genre sastera dari perspektif sosiostilistik. Dlm. Mohd Sharifudin Yusof, Arba'ie Sujud \& Zaitul Azma Zainon Hamzah (Eds.), Penyelidikan linguistik bahasa dan budaya: Pemupukan perpaduan (h. 402-411). Serdang: Universiti Putra Malaysia.

Azean Idruwani Idrus \& Zaitul Azma Zainon Hamzah. (2011). Analisis kesilapan dalam laporan media: Morfologi dan sintaksis. In. Kamariah Kamaruddin, Arba'ie Sujud, Zaitul Azma Zainon Hamzah \& Samsina Abdul Rahman (Eds.). Kelestarian bahasa: Satu rumpun satu ikatan (h. 18-31). Serdang: Penerbit UPM.

Baker-Woods G., Dodd J. E., Ford K., Keller K., Plumley J.Jr., Smeyak G. P., Walsh-Childers K. (1997). Mass media writing: An introduction. Arizona: Gorsuch Scarisbrick.

Bucaria, C. (2004). Lexical and syntactic ambiguity as a source of humor: The case of newspaper headlines. Humor-International Journal of Humor Research, 17(3), 279-310.

Ehineni, T. O. (2014). Lexical, structural and rhetorical features of Nigerian English print media. Journal of Arts and Humanities, 3(11), 26-32.

Eneng Khairunnisa. (2012). Penerapan bahasa jurnalistik pada berita utama "Straight News" di surat kabar "Radar Bekasi" edisi 1-5 Oktober 2012. Tesis Sarjana. Universitas Islam Negeri Syarif Hidayatullah, Jakarta.

Goay, T. C., Choo, S. T. \& Zainuddin Ahmad. (2006). Teks pra-U Bahasa Melayu STPM: Kertas 1. Petaling Jaya: Pearson Malaysia.

Hamidah Abdul Wahab. (2012). Aspek kelewahan dalam laporan akhbar atas talian. Issues in Languages Studies, 1(2), 24-31.

Hasna A Rahmatu. (2013). Kohesi dalam wacana opini media tadulako. Jurnal Bahasa dan Sastra , 2(1), 1-15.

Itule, B.D. \& Anderson, D.A. (2007). News writing and reporting for today media. New York: McGraw-Hill International Editions.

Jeniri Amir. (2005). Dari budaya ke media: mengangkat suara pinggiran di Sarawak. Kota Samarahan: The Sarawak Press Sdn Bhd.

Julia Wirza Mohd Zawawi \& Kee, C.P. (2013). Penentuan bingkai berita keselamatan awam dari penelitian respon kognisi dan ekspresi audiens. Jurnal Komunikasi, 29(2), 141-158.

Kamus Dewan Edisi Keempat. (2015). Kuala Lumpur: Dewan Bahasa dan Pustaka.

Kartini Abd. Wahab \& Zulkifley Hamid. (2015). Hambatan memahami bahasa: satu penelitian ke atas teks berita dalam talian berbahasa Indonesia, Tempo.Co. Jurnal Komunikasi, 31(2), 493-514.

Khairol Anuar Harith Fadzillah. (2016). Bahasa dalam penulisan rencana. Dewan Bahasa, 16(8), 49-52. 
Leki, I., \& Carson, J. G. (1994). Students' perceptions of EAP writing instruction and writing needs across the disciplines. Dlm. TESOL Quarterly, 28(1), 81-101.

Li, Y., Zhang, D., \& Du, W. (2014). A case analysis of lexical features in english broadsheets and tabloids. International Journal of English Linguistics, 4(4), 115-122.

Milton, J. (2013). Measuring the contribution of vocabulary knowledge to proficiency in the four skills. Dlm C. Bardel, C. Lindqvist, \& B. Laufer, (Eds.). L2 Vocabulary acquisition, knowledge and use: New perspectives on assesment and corpus analysis, European Second Language Association (h. 57-78). Eurosla Monographs Series 2.

Mior Kamarul Shahid. (2015). Bahasa: Sejauh manakah media peduli? Dewan Bahasa, 15(3), 8-10.

Mohd Hazreen Shah Hassan, Sharil Nizam Sha'ri \& Nor Azuwan Yaakob. (2019). Keberkesanan penggunaan bahasa dalam akhbar Melayu: Tindak balas strategik terhadap literasi kesihatan dalam kalangan pembaca. The Journal Of Humanities And Social Sciences, 6(1), 95-109.

Mohd Rajib Ab Ghani \& Faridah Ibrahim. (1987). Objektiviti bahasa dalam kewartawanan. Jurnal Komunikasi, 3(1), 13-25.

Mohidin Malek. (2016). Serlahan kebitaraan bangsa. Dewan Bahasa, 16(10), 3.

Mus Chairil Samani. (1992). Sumber berita: Analisis isi kandungan empat akhbar harian nasional Malaysia. Jurnal Komunikasi, 8(1), 49-63.

Mus Chairil Samani. (1997). Penulisan rencana berkesan. Kuala Lumpur: Dewan Bahasa dan Pustaka.

Nik Safiah Karim, Farid M. Onn, Hashim Musa \& Abdul Hamid Mahmood. (2008). Tatabahasa Dewan Edisi Ketiga. Kuala Lumpur: Dewan Bahasa dan Pustaka.

Noor Aina Dani. (2008). Modul kursus BBM3413: Kaedah penyelidikan bahasa Melayu. Serdang: Penerbit UPM.

Noordin Zakaria. (2012). Bahasa kewartawanan: Membersihkan "sampah". Dewan Bahasa, 12(11), 26-30.

Nor Azuwan Yaakob. (2008). Penulisan kewartawanan Melayu: Kajian retorik terhadap kandungan akhbar Berita Harian (1957-1999). Tesis Doktor Falsafah. Universiti Malaya.

Nurhidayah. (2006). Bahasa Indonesia dalam karya ilmiah. FBS Universitas Negeri Yogyakarta.

Paimah Atoma. (2004). Gaya persembahan dan kemahiran penulisan. Jurnal Kemanusiaan, 2(1), 18-26.

Park, B. (2012). Does the PVLT provide an accurate measure of productive vocabulary knowledge? English Teaching, 67(2), 159-183.

Roosfa Hashim. (2011). Daripada tesis kepada buku. Serdang: Penerbit UPM.

Roslan Abdul Wahid \& Siti Khariah Mohd Zubir. (2007). Analisis kepengarangan J.M Aziz dan nilai-nilai kemanusiaan dalam sajak-sajak J.M AZIZ berdasarkan pendekatan sistem pemikiran bersepadu 4L (luhur, lahir, logik dan lateral). Tesis Doktor Falsafah. Universiti Pendidikan Sultan Idris Shah.

Sharil Nizam Sha'ri. (2010). Aplikasi teori dan format penyuntingan bahan linear dalam surat khabar bahasa Melayu. Tesis Doktor Falsafah. Universiti Putra Malaysia.

Sulaiman Masri \& Razali Ayob. (2002). Komunikasi Kewartawanan: Penulisan berita, rencana dan ulasan. Kuala Lumpur: Utusan Pubication \& Distributors Sdn Bhd. 
Waterhouse, K. (1989). Waterhouse on newspaper style. London: Penguin.

Zaharani Ahmad. (2002). Perubahan morfologi dalam tiga edisi Kamus Dewan. Jurnal Bahasa, 2(3), 416-429.

Zunita Mohamad Maskor, Harun Baharudin \& Maimun Aqsha Lubis. (2016). Pengetahuan kosa kata produktif dalam kemahiran menulis. PROSIDING Wacana Pendidikan Islam Siri ke-11 (WPI11), 857-866.

\section{PENGHARGAAN}

Artikel ini adalah daripada kajian yang dibiayai di bawah projek penyelidikan Geran GPIPS/2017/9515800 yang diterima daripada Universiti Putra Malaysia. 